\title{
Scientists of the future: an analysis of talented students' interests
}

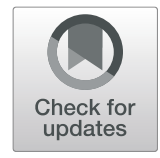

\author{
Tim N. Höffler ${ }^{*}$ (D), Christine Köhler and Ilka Parchmann
}

\begin{abstract}
Background: Nowadays, scientists not only need to be creative, resourceful, and inventive regarding their research questions and need to understand their field and research methods, but also need to know how to teach, how to catalog, how to fill out proposal forms, and much more. The main goal of this study was to investigate and compare science interest profiles of different groups of students, focusing both on successful participants in science competitions and on possible gender differences. We expected that successful participants in science competitions would generally have greater interests in scientific activities than non-participants but were especially interested in such areas we expect from successful scientists today, thereby helping us judge the design of successful enrichment measures.

Results: Significant mean differences in interest in science activities between participants and non-participants of science competitions were found on six of seven dimensions as well as regarding in-school activities, activities in enrichment measures, and vocational interests. The differences were especially large concerning investigative, social, enterprising, and networking activities. Moreover, we found differences between girls and boys on the social and artistic dimensions, meaning that girls were significantly more interested in science activities which also had an artistic and creative aspect such as drawing or a social aspect such as teaching.

Conclusions: We not only found overall differences to-be-expected favoring the participants, but also could also identify specific profiles. Especially large differences were consistently found in those areas which could be regarded as especially important for most researchers. Our findings might help developing measures and activities to foster the interest in science activities for "regular" students as well as for especially talented students.
\end{abstract}

Keywords: Competitions, RIASEC, Science interest, Talented students, Sender differences

\section{Background}

Often, many non-scientists still have the perception that scientists are usually Einstein-like men in white lab-coats who work maniacally with colorful chemicals (Barman, 1999; Painter, Jones, Tretter, \& Kubasko, 2006). Of course, while still a prevalent depiction in media, this is largely untrue these days (and has been untrue for a long time). In modern science, scientists usually must be more than excellent researchers, working on their own in their labs. They need to be able to cooperate, often even across disciplines; they need to communicate their ideas and findings to different stakeholders who decide about their funding; and they need to teach the next generation to follow in their footsteps. Scientists' career

\footnotetext{
* Correspondence: hoeffler@ipn.uni-kiel.de

Leibniz Institute for Science and Mathematics Education (IPN), Olshausenstr. 62, 24118 Kiel, Germany
}

profiles have expanded significantly over the decades (e.g., Anderson et al., 2011; Andrews, Weaver, Hanley, Shamatha, \& Melton, 2005; O'Leary, 2012; Wilding, 1995). They not only need to be creative, to understand their field and research methods, and to be resourceful and inventive regarding their research questions (Stefanadis, 2006), they also need to know how to teach, how to catalog, how to fill out proposal forms, how to present their results to different audiences, how to collaborate with colleagues around the world, and more (Stamer, Pönicke, Höffler, Schwarzer, \& Parchmann, 2019). This certainly does not correspond with every scientists' interests, tasks, and abilities, and many scientists often complain about too many duties keeping them away from their "real research," some having rather narrowly defined duties. Still, the field as it is today and probably will be in the future usually requires scientists with 
diverse competencies and interests. Thus, it is of utmost importance when scouting and educating future scientists to look beyond mere knowledge and to also search for and foster additional skills, traits, and interests necessary for good or even excellent scientists. This already begins at the school level.

Beyond school education, a large number of enrichment measures aim to identify such skills and interests in young people and to further support them-among them, science labs (de Jong, Linn, \& Zacharia, 2013), summer schools (Markowitz, 2004), and science competitions (Höffler, Bonin, \& Parchmann, 2017). However, it is an open question if or to what degree such enrichment measures actually achieve these goals, especially in a broader sense when not only highly gifted students are focused on (Stake \& Mares, 2001). While competitions, for instance, might raise the self-perception of successful students and enhance their willingness to pursue a career in science (Feist, 2006; Subotnik \& Steiner, 1994; Tirri \& Nokelainen, 2010), they might also result in a decrease of interest in any further scientific activities for non-successful participants. More research is needed to better identify conditions and effects of different enrichment measures to better guide potential young talents, thereby developing and advising suitable activities for different purposes.

The question is as follows: Are potential young talents reached with existing enrichment measures, and in return, do they meet the requirements of modern science?

We investigated this question regarding students participating in science competitions as a special form of enrichment measures (Taber, 2007) in comparison to non-participants. One research goal was to identify profiles of interest for different groups which could later be used to develop adaptive support programs. Thus, it was necessary to develop a suitable theoretical framework and instrument which represents the different activities required in modern science. For this purpose, we used a new instrument loosely based on John Holland's "RIASEC-model" (Holland, 1985, 1997; Dierks, Höffler, \& Parchmann, 2014; Dierks, Höffler, Blankenburg, Peters, \& Parchmann, 2016). The acronym "RIASEC" stands for different fields of interests correlating with different demands of professions (the "S," for example, stands for "social" and refers to interests in helping other people or doing something good for society and hence, for professions such as social workers, teachers, and nurses). While the original model was used to classify personality types, we only used the surface structure to measure interests in different science activities broadly attributed to the dimensions. Interests are often differentiated between situational interests and individual interests (Hidi, 1990; Krapp \& Prenzel, 2011). While situational interest is more short-lived and can be characterized by the motivational state of being interested, individual interests describe a more stable inclination to engage in a certain activity. Similar to the original model, we consider the interests measured in our study to be relatively stable individual interests. Whereas the original model limited science professions to the attributes "realistic" and "investigative," considering the broad field of science and scientists of today, we connected all attributes to scientists' activities (Fig. 1).

This new model and instrument represents a broader scope of current requirements of scientists; thus, we can compare interest profiles of successful participants in science competitions with those of regular students, keeping an eye on gender differences and their implications for enrichment measures.

\section{Research goals}

The main goal of this study was to investigate and compare science interest profiles of different groups of students, focusing both on successful participants in science competitions and on possible gender differences. We expected that successful participants in science competitions would generally have a greater interest in scientific activities than non-participants but were especially interested in the different RIASEC+N dimensions and expected distinct profiles which should coincide with such interests we expect from successful scientists today, namely, specific interest in investigative, social, and networking activities. We regarded gender differences as an additional research interest where we expected mean profile differences, that is, we expected girls to have a greater interest in artistic and social scientific activities, while boys might be more interested in enterprising and realistic scientific activities (Jones, Howe, \& Rua, 2000; Lupart, Cannon, \& Telfer, 2004).

\section{Materials and methods Participants}

We included $N=988$ students from all over Germany in the sample. Among them were 63 participants from the German national final of the International Junior Science Olympiad (IJSO), and 925 students from regular schools, mostly from the highest track of secondary schooling in Germany ("Gymnasium"). Of those, 510 had never participated in any science or mathematics competition, and 415 stated that they had at least once participated. We handled those two groups separately for a more detailed analysis. The IJSO is an international science competition in which students from approximately 50 countries participate each year. It includes biology, chemistry, and physics and aims to promote students' interest in science as well as intercultural understanding (Petersen, Blankenburg, \& Höffler, 2018). In Germany, the six team members of the international competition used to be chosen in a national pre-competition in three 


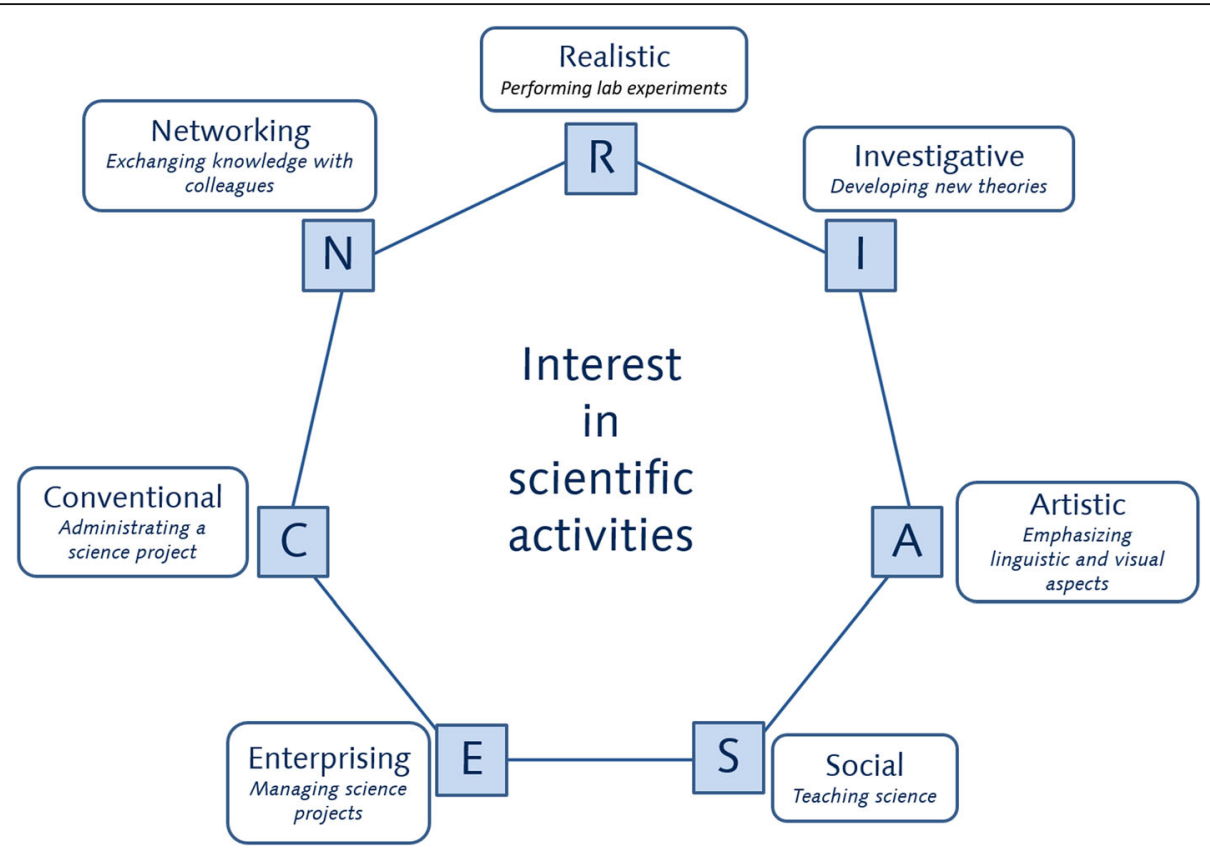

Fig. 1. RIASEC+N model. Interest in scientific activities according to the adapted RIASEC+N model

rounds (presently, the procedure involves four rounds). From approximately 3500 students in the first round, about 500 students reach the second round and 45 the third. The competition requires theoretical knowledge and experimental competences of the students. It is open for students up to the age of 15 .

The average age of the entire sample was 14.7 years. $43.4 \%$ of all participants were female.

\section{Instruments}

Interest was measured with an adapted version of Holland's (1985) RIASEC-questionnaire usually used for measuring personality types for different professions and which classifies participants into the six vocational dimensions: realistic ("doers"; typical vocation: mechanic), investigative ("thinkers"; e.g., scientist), artistic ("creators"; e.g., artist), social ("helpers"; e.g., teacher), enterprising ("persuaders"; e.g., businesswoman), and conventional ("organizers"; e.g., accountant). The version by Dierks et al. (2014, 2016) adapted those broad categories to typical present scientists' activities, so that students' vocational interests in science activities could be captured with a much more fine-grained instrument including activities from all six categories (and a seventh, networking, which reflects the peer-to-peer exchange with colleagues). It is important to note that in contrast to Holland's original model, the new instrument does not measure personality types in any way but is exclusively interested in scientists' typical activities, clustered in seven dimensions. For example, regarding the realistic dimension, the instrument measures the interest in activities such as performing lab activities; regarding the investigative dimension, solving theoretical problems; regarding the artistic dimension, emphasizing linguistic and visual aspects of science topics; regarding the social dimension, teaching of and explaining to others; regarding the enterprising dimension, managing science group works; regarding the conventional dimension, organizing and managing the chemical storage; and regarding the networking dimension, discussing science topics with like-minded classmates (for more examples, please refer to Dierks et al., 2016).

The instrument consists of 28 items (thus, four items per dimension). Furthermore, all items were to be answered separately for interest in the specific activity in school, in an enrichment measure, and in a possible occupation later in life. Thus, 84 items measured interest in science activities in seven dimensions and regarding three different environments. To quote Dierks et al. (2016):

For the adaption, the attributes of the original model were connected to matching activities for sciencerelated vocations and activities. For example, in the original RIASEC-model, the realistic dimension describes mostly manual and technical activities. In a science-related occupation, this could be the performance of practical lab work. Analogous to these items, science-related school activities and sciencerelated enrichment activities were chosen. In school, for instance, lab work is performed, but mainly with a focus on experiments following given instructions. Lab work in enrichment activities can also implicate more complex and open experiments. The differences 
in the three environments therefore consist of different actual tasks to ensure a valid adaption of the test items.

Participants answered all items on a 4-point Likert scale ("This interests me very much - this interests me quite a bit - this interests me a little - this does not interest me at all"). Reliabilities were mostly satisfactory and in the same range as in previous studies from Cronbach's $\alpha=0.66$ to 0.86 . When bundled together into the three environments, school, enrichment, and vocational activities, the reliabilities range from $\alpha=0.86$ to 0.93 .

Regarding validity, previous studies (Dierks et al., 2016) showed a strong relation between a general interest in science subjects and mathematics and interest in science activities, measured with the RIASEC $+\mathrm{N}$ instrument. To preview some of the results, this is also the case in the current study: The seven RIASEC $+\mathrm{N}$ scales correlate significantly with general interest in science subjects between $r=0.26$ (Conventional) and $r=0.53$ (Investigating and Networking). Moreover, several times, the structure of the instrument has been shown to be valid by calculating confirmatory factor analysis models with very good goodness-of-fit indices in three studies with different participants (Dierks et al., 2016: grades 8-12; Blankenburg, Höffler, \& Parchmann, 2016a: grade 6; Höft, Bernholt, Blankenburg, \& Winberg, 2019: grades 5-11). Lastly, a study which asked science professors to judge the validity of their activities regarding the seven dimensions confirmed the general structure of the model even further (Stamer et al., 2019).

No more than $20 \mathrm{~min}$ were required to fill out the questionnaire.

\section{Data analysis}

Data was analyzed with SPSS. One-factorial analyses of variance were calculated to compare all three groups. Post-hoc pair-wise comparisons with Sidak-correction (alpha-adjustment) served to compare two groups. Alphaadjustment is recommended when calculating multiple comparisons in order to reduce the risk of a Type I error by conflating the alpha level (Aickin \& Gensler, 1996). For calculating variance homogeneity, one of the conditions for calculating analyses of variance, the Levene-test was applied (Levene, 1960). If variance homogeneity was not reached, Welch tests were used to check whether the result was robust (Welch, 1951), as those tests do not require equal variances. Kolmogorov-Smirnov tests were applied to check for normal distribution of the data. When those indicated non-normality for the dependent variables, additional non-parametric tests (Mann-Whitney $U$ tests; Mann \& Whitney, 1947) were calculated which do not require the assumption of normal distribution. In all cases, those led to comparable results as the pair-wise comparisons reported below (which is often the case; cf. Fay \& Proschan, 2010). Two-factorial analyses of variance were calculated when comparing two independent variables.

\section{Results}

Several significant differences between all three groups were found (Fig. 2) when comparing the profiles of xstudents' interests. This was true for in-school activities, enrichment measures, and for vocational interests (Table. 1).

Regarding vocational interests, a number of significant effects could be found, the largest in differences in the

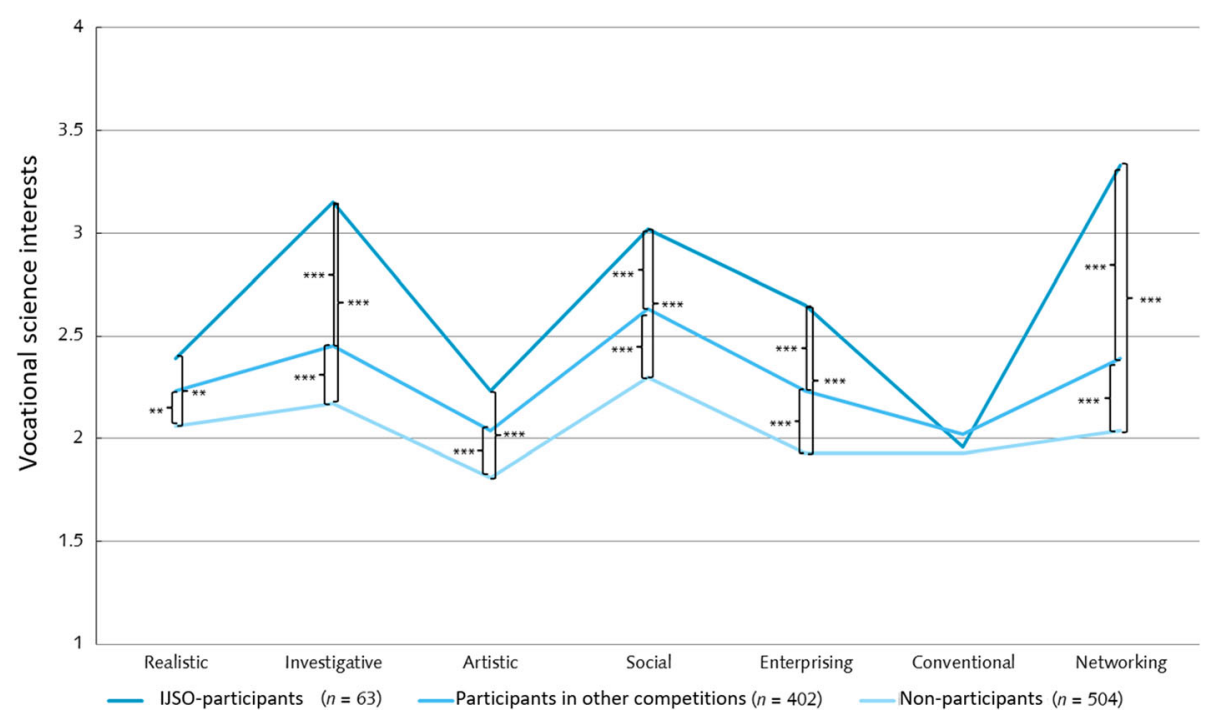

Fig. 2. Vocational science interest profiles. Interest profiles of IJSO participants, non-participants, and participants in other science or mathematics competitions in comparison. Statistically significant differences are marked $\left({ }^{* *} p<0.001 ;{ }^{* *} p<0.01\right)$. 
Table 1 Mean differences and results of analyses of mean differences of IJSO participants, non-participants, and participants in other science or mathematics competitions on the RIASEC+N dimensions for in-school activities, enrichment measures, and for vocational interests. Assessment of the effsize (small to large) according to Cohen (1988).

\begin{tabular}{|c|c|c|c|c|c|c|c|}
\hline Type of activity & Dimension & MS & $d f$ & $F$ & $p$ & $\eta_{p}^{2}$ & Effect \\
\hline \multirow[t]{7}{*}{ Vocational } & Realistic & 4.85 & 2 & 9.33 & $<0.001$ & 0.019 & Small \\
\hline & Investigative & 30.19 & 2 & 47.18 & $<0.001$ & 0.089 & Medium \\
\hline & Artistic & 8.96 & 2 & 18.41 & $<0.001$ & 0.037 & Small \\
\hline & Social & 21.59 & 2 & 33.71 & $<0.001$ & 0.066 & Medium \\
\hline & Enterprising & 20.00 & 2 & 34.30 & $<0.001$ & 0.067 & Medium \\
\hline & Conventional & 0.91 & 2 & 1.84 & 0.160 & - & None \\
\hline & Networking & 51.81 & 2 & 73.53 & $<0.001$ & 0.133 & Large \\
\hline \multirow[t]{7}{*}{ In-school } & Realistic & 0.26 & 2 & 0.75 & 0.474 & - & None \\
\hline & Investigative & 11.57 & 2 & 27.72 & $<0.001$ & 0.053 & $\begin{array}{l}\text { Small to } \\
\text { medium }\end{array}$ \\
\hline & Artistic & 6.04 & 2 & 13.53 & $<0.001$ & 0.027 & Small \\
\hline & Social & 9.48 & 2 & 18.49 & $<0.001$ & 0.036 & Small \\
\hline & Enterprising & 10.66 & 2 & 21.77 & $<0.001$ & 0.043 & Small \\
\hline & Conventional & 0.12 & 2 & 0.30 & 0.740 & - & None \\
\hline & Networking & 32.14 & 2 & 58.40 & $<0.001$ & 0.107 & $\begin{array}{l}\text { Medium } \\
\text { to large }\end{array}$ \\
\hline \multirow[t]{7}{*}{ Enrichment } & Realistic & 16.37 & 2 & 33.98 & $<0.001$ & 0.066 & Medium \\
\hline & Investigative & 41.99 & 2 & 72.87 & $<0.001$ & 0.132 & Large \\
\hline & Artistic & 18.30 & 2 & 39.58 & $<0.001$ & 0.076 & Medium \\
\hline & Social & 25.44 & 2 & 42.69 & $<0.001$ & 0.082 & Medium \\
\hline & Enterprising & 21.35 & 2 & 41.83 & $<0.001$ & 0.081 & Medium \\
\hline & Conventional & 3.73 & 2 & 8.36 & $<0.001$ & 0.017 & Small \\
\hline & Networking & 63.13 & 2 & 99.57 & $<0.001$ & 0.172 & Large \\
\hline
\end{tabular}

investigative, social, enterprising, and networking dimensions. To a lesser degree, this is also true for activities in school and in enrichment measures. Medium to large effect sizes (Table 1) confirm the statistical meaningfulness of those differences.

Regarding differences between girls and boys (exemplarily, Fig. 3 for interest in in-school activities), girls have significantly stronger interests in science activities than boys when they emphasize artistic aspects, such as illustrating scientific topics esthetically or drawing experimental setups or preparations. This is true for interest in artistic science in-school activities $(F(1,973)=23.20, p<0.001$, $\left.\eta_{p}^{2}=0.023\right)$, artistic science enrichment activities ( $F(1$, $\left.952)=20.86, p<0.001, \eta_{p}^{2}=0.021\right)$, and vocational interests $\left(F(1,955)=5.43, p=0.02, \eta_{p}^{2}=0.006\right)$. To a lesser degree, the same is true for social science activities, but here only for in-school activities $(F(1,972)=8.11, p=0.004$, $\left.\eta_{p}^{2}=0.008\right)$ and enrichment activities $(F(1,950)=7.75$, $\left.p=0.005, \eta_{p}^{2}=0.008\right)$, not for vocational interests $(F(1$, $955)=2.43, p=0.19)$. With the exception of enterprising science activities in enrichment activities $(F(1,947)=$ 4.17, $\left.p=0.041, \eta_{p}^{2}=0.004\right)$, no other differences between girls and boys on the other dimensions were statistically significant.

\section{Discussion}

Using an elaborated model of interest in science activities, we aimed to compare interest profiles of talented participants of a ScienceOlympiad with other students' profiles. First of all, the RIASEC+N instrument, which we now have used in four different studies, once again showed promise and led to interesting results. Its small to medium correlations with general interest in science subjects might be an indication that we indeed measured interest in science activities, but more fine-grained than with conventional instruments. Thus, this approach might provide students with a more authentic view on science (see also Stamer et al., 2019) and might make them realize that science is more diverse than they thought.

Furthermore, we not only discovered to-be-expected overall differences favoring the participants, but also could identify specific profiles. While those were not strictly congruent when comparing vocational interests, interests in science school activities, and in science enrichment 


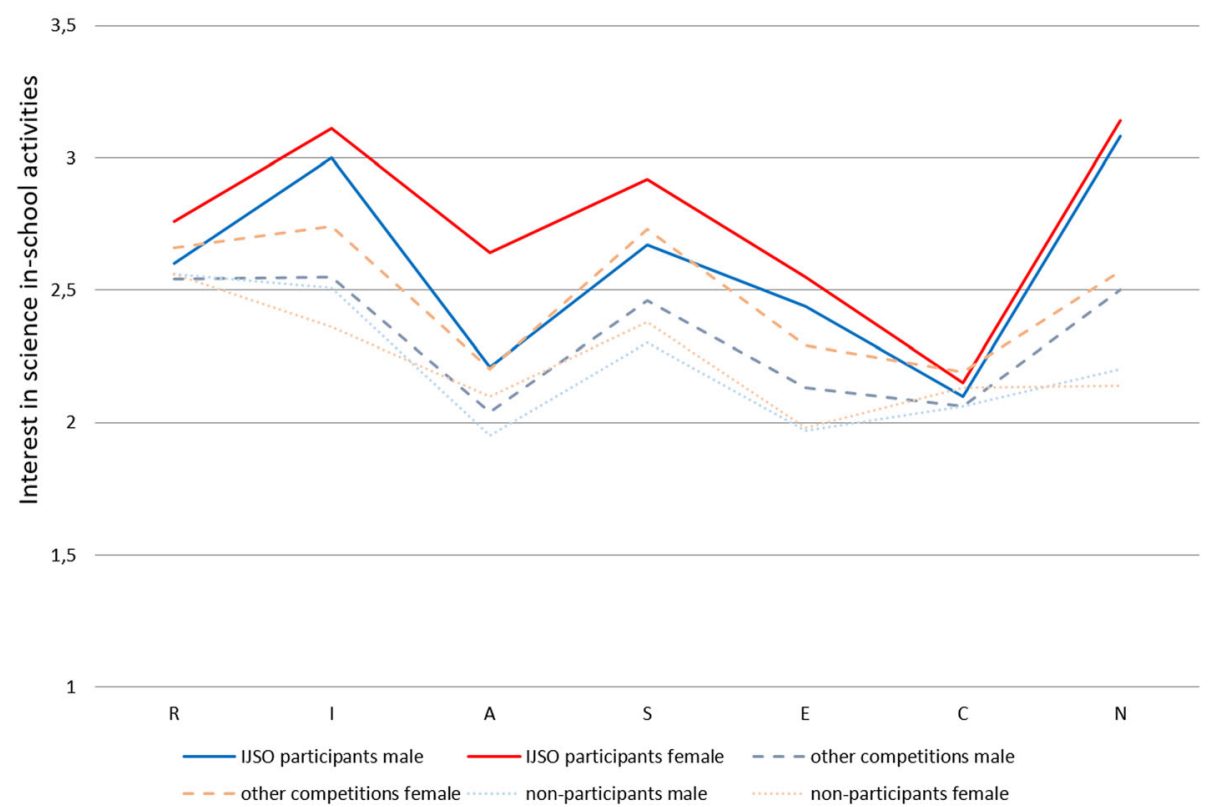

Fig. 3. Gender profiles of interest in science in-school activities. Interest profiles of IJSO-participating, non-participating, and in other science and mathematics participating girls and boys in realistic, investigative, artistic, social, enterprising, conventional, and networking science activities.

activities, especially large differences, were consistently found in the areas of investigative, social, enterprising, and networking activities. One might claim that those are interests especially important for future scientists. Furthermore, our findings might help to develop vocational, in-school, and enrichment measures and activities to foster the interest in science activities not only for "regular" students, but also for talented students in science. It is noteworthy that IJSO participants have the highest interest in investigative, social, and networking activities. These findings emphasize the importance of enrichment activities like science competitions which have the potential to especially promote networking activities. That those students who had already participated in one or more science or mathematics competitions in the past had significantly stronger interests than those who did not, to some extent, further corroborates this interpretation. (However, we cannot know if the participation in science competitions has led to higher interest or if only students with higher interest participated in science competitions-probably a combination of both.) In any case, thinking about in-school activities which might support highly interested students, for example, to exchange their knowledge (i.e., networking activities) with students from other classes might also be helpful. It is certainly highly interesting that the networking dimension plays such a strong role for successful students of STEM, that is, IJSO participants. Schools might want to apply this finding by promoting any kind of networking science activities, by rewarding participation in extracurricular STEM projects and by bringing together interested students. Indeed, it has already been shown that a previous participation in science competitions can increase the probability of success (Urhahne, Ho, Parchmann, \& Nick, 2012) and that competitions can be used as continuous strategies to foster students' interests in science (Blankenburg, Höffler, Peters, \& Parchmann, 2016b). Thus, this newly established science interest dimension warrants further research and should also be focused on in future interventions.

Moreover, we found girls to have a significantly stronger interest in artistic and social science activities than boys. While this is nothing new for artistic activities in general (Lupart et al., 2004), it is noteworthy that such an interest seems to extend to artistic and social science activities (see also Lubinski \& Benbow, 2006; Blankenburg et al., 2016a). Thus, educators might want to think about developing gender-specific enrichment measures and in-school activities focusing on such science activities which have a special appeal to girls. Such enrichment or in-school activities might trigger a stronger interest in science itself, thus presenting a possible method to close still existing gender gaps in science competitions, science courses, and science as a profession (e.g., Reis \& Park, 2001; Steegh, Höffler, Keller, \& Parchmann, 2019). On the other hand, this finding could be seen as a grave shortcoming of the boys' interest profiles: As social and artistic science 
activities are important parts of today's scientists' work fields (Stamer et al., 2019) and the artistic dimension developed in childhood in particular is very important for success among adult science, technology, engineering, mathematics, and medicine (STEMM) professionals (Root-Bernstein et al., 2019), serious efforts might be in order to promote boys' interests in these fields.

As a limitation to the current study, it is unfortunate that only a small part of our sample were participants in the IJSO. More would have been preferable, of course. However, resulting variance heterogeneities were countered by using the Welch test, thus making the results sufficiently trustworthy. The reliabilities of some scales were also lower than one would have preferred; therefore, interpretations should be made with some caution.

\section{Conclusion}

Who are the exceptional scientists of tomorrow who will bring us creative solutions for our world's societal and environmental problems? They certainly must have an extraordinary interest in finding new ideas and developing new approaches and hence are investigative. However, they must also show an interest in cooperating with other experts, as today's and future demands are far too complex to be solved by individuals alone. And they need to ensure that their findings are applicable to many people and be able to teach those findings.

Looking at our outcomes, the successful participants more or less display the profile we described earlier as important for responsible scientists, providing high interests especially in investigative, social, and networking activities. They also have a rather strong interest in enterprising science activities, which we did not expect, but which also makes sense, as managing science groups is something important with which the IJSO participants should already have some experience. Apparently, they do not participate in the competition just for winning. The results also stand in contrast to former findings reporting stereotypical outcomes like strong interests in social activities for girls and strong interests in investigative activities for boys (Vock, Köller, \& Nagy, 2012). The adapted model and new instrument therefore promises more differentiated analyses and insights into young students' interests in science to better adapt fostering measures and thereby get more talented students into science and the whole STEM field-as future scientists or as open-minded citizens.

\section{Abbreviations}

IJSO: International Junior Science Olympiad; RIASEC $(+N)$ : The letters stand for different dimensions of interest in (science) activities: Realistic, Investigative, Artistic, Social, Enterprising, Conventional, Networking; STEM(M): Science, technology, engineering, mathematics, (medicine)

\section{Acknowledgements}

The authors wish to thank Pay O. Dierks and Wilfried Wentorf for their valuable prior work which laid the base for parts of the current manuscript.

\section{Authors' contributions}

TH drafted this manuscript, analyzed the data, and was part of the conceptual team. CK acquired the data, was part of the conceptual team, and substantially revised the manuscript. IP supervised the conception and substantially contributed to the manuscript. All authors read and approved the final manuscript.

\section{Funding}

This project was funded by the German Research Foundation (DFG), grant no. HO 4303/5-1.

\section{Availability of data and materials \\ The dataset used during the current study is available from the corresponding author on reasonable request.}

\section{Competing interests}

The authors declare that they have no competing interests.

Received: 30 January 2019 Accepted: 13 August 2019

Published online: 03 September 2019

\section{References}

Aickin, M., \& Gensler, H. (1996). Adjusting for multiple testing when reporting research results: the Bonferroni vs Holm methods. American Journal of Public Health, 86(5), 726-728.

Anderson, W. A., et al. (2011). Changing the culture of science education at research universities. Science, 331(6014), 152-153.

Andrews, E., Weaver, A., Hanley, D., Shamatha, J., \& Melton, G. (2005). Scientists and public outreach: Participation, motivations, and impediments. Journal of Geoscience Education, 53(3), 281-293.

Barman, C. R. (1999). Students' views about scientists and school science: Engaging K-8 teachers in a national study. Journal of Science Teacher Education, 10(1), 43-54

Blankenburg, J. S., Höffler, T. N., \& Parchmann, I. (2016a). Fostering today what is needed tomorrow: Investigating students' interest in science. Science Education, 100(2), 364-391.

Blankenburg, J. S., Höffler, T. N., Peters, H., \& Parchmann, I. (2016b). The effectiveness of a project day to introduce sixth grade students to science competitions. Research in Science \& Technological Education, 34(3), 342-358.

Cohen, J. (1988). Statistical power analysis for the behavioral sciences (2nd ed.). Mahwah: Lawrence Erlbaum Associates.

de Jong, T., Linn, M. C., \& Zacharia, Z. C. (2013). Physical and virtual laboratories in science and engineering education. Science, 340, 305-308.

Dierks, P. O., Höffler, T. N., Blankenburg, J. S., Peters, H., \& Parchmann, I. (2016). Interest in science: A RIASEC-based analysis of students' interests. International Journal of Science Education, 38, 238-258.

Dierks, P. O., Höffler, T. N., \& Parchmann, I. (2014). Profiling interest of students in science: Learning in school and beyond. Research in Science \& Technological Education, 32, 97-114.

Fay, M. P., \& Proschan, M. A. (2010). Wilcoxon-Mann-Whitney or t-test? On assumptions for hypothesis tests and multiple interpretations of decision rules. Statistics surveys, 4, 1-39. https://doi.org/10.1214/09-SS051.

Feist, G. J. (2006). The development of scientific talent in Westinghouse finalists and members of the National Academy of Sciences. Journal of Adult Development, 13(1), 23-35.

Hidi, S. (1990). Interest and its contribution as a mental resource for learning. Review of Educational Research, 60, 549-571.

Höffler, T. N., Bonin, V., \& Parchmann, I. (2017). Science vs. sports: Motivation and self-concepts of participants in different school competitions. International Journal of Science and Mathematics Education, 15, 817-836.

Höft, L., Bernholt, S., Blankenburg, J. S., \& Winberg, M. (2019). Knowing more about things you care less about: Cross-sectional analysis of the opposing trend and interplay between conceptual understanding and interest in secondary school chemistry. Journal of Research in Science Teaching, 56(2), 184-210.

Holland, J. L. (1985). Making vocational choices: A theory of vocational personalities and work environments. Englewood Cliffs, NJ: Prentice-Hall.

Holland, J. L. (1997). Making vocational choices: A theory of vocational personalities and work environments. Edessa, FL: Psychological Assessment Resources. 
Jones, M. G., Howe, A., \& Rua, M. J. (2000). Gender differences in students' experiences, interests, and attitudes toward science and scientists. Science Education, 84(2), 180-192.

Krapp, A., \& Prenzel, M. (2011). Research on interest in science: Theories, methods, and findings. International Journal of Science Education, 33(1), 27-50.

Levene, H. (1960). Robust tests for equality of variance. In O. Ingram, H. Hotelling, et al. (Eds.), Contributions to Probability and Statistics: Essays in Honor of Harold Hotelling (pp. 278-292). Stanford: Stanford University Press.

Lubinski, D., \& Benbow, C. P. (2006). Study of mathematically precocious youth after 35 years: Uncovering antecedents for the development of math-science expertise. Perspectives on psychological science, 1(4), 316-345.

Lupart, J. L., Cannon, E., \& Telfer, J. A. (2004). Gender differences in adolescent academic achievement, interests, values and life-role expectations. High Ability Studies, 15(1), 25-42.

Mann, H. B., \& Whitney, D. R. (1947). On a test of whether one of two random variables is stochastically larger than the other. The Annals of Mathematical Statistics, 18(1), 50-60.

Markowitz, D. G. (2004). Evaluation of the long-term impact of a university high school summer science program on students' interest and perceived abilities in science. Journal of Science Education and Technology, 13, 395-407 2004.

O'Leary, S. (2012). Impact of entrepreneurship teaching in higher education on the employability of scientists and engineers. Industry and Higher Education, 26(6), 431-442.

Painter, J., Jones, M. G., Tretter, T. R., \& Kubasko, D. (2006). Pulling back the curtain: Uncovering and changing students' perceptions of scientists. School Science and Mathematics, 106(4), 181-190.

Petersen, S., Blankenburg, J. S., \& Höffler, T. N. (2018). Challenging gifted students in science - the German Science Olympiads. In K. S. Taber, M. Sumida, \& L. McClure (Eds.), Teaching Gifted Learners in STEM Subjects: Developing talent in science, technology, engineering and mathematics (pp. 157-170). London: Routledge.

Reis, S. M., \& Park, S. (2001). Gender differences in high-achieving student in math and science. Journal for the Education of the Gifted, 25, 52-73.

Root-Bernstein, R., Peruski, A., Vandyke, M., Root-Bernstein, M., Lamore, R., Schweitzer, J., Lawton, J., \& Roraback, E. (2019). Differences in male and female arts and crafts avocations in the early training and patenting activity of STEMM professionals. Technology \& Innovation, 20(3), 197-219.

Stake, J. E., \& Mares, K. R. (2001). Science enrichment programs for gifted high school girls and boys: Predictors of program impact on science confidence and motivation. Journal of Research in Science Teaching, 38, 1065-1088.

Stamer, I., Pönicke, H., Höffler, T. N., Schwarzer, S., \& Parchmann, I. (2019). Development \& validation of scientific video vignettes to promote perception of authentic science in student laboratories. Research in Science \& Technological Education. https://doi.org/10.1080/02635143.2019.1600491.

Steegh, A., Höffler, T. N., Keller, M., \& Parchmann, I. (2019). Gender differences in mathematics and science competitions: A systematic review. Journal of Research in Science Teaching. https://doi.org/10.1002/tea.21580.

Stefanadis, C. I. (2006). Characteristics of the good researcher: Innate talent or acquired skills? Hellenic Journal of Cardiology, 47, 52-53 (2006).

Subotnik, R. F., \& Steiner, C. L. (1994). Adult manifestations of adolescent talent in science: A longitudinal study of 1983 Westinghouse Science Talent Search winners. In R. F. Subotnik \& K. D. Arnold (Eds.), Beyond Terman: Contemporary longitudinal studies of giftedness and talent (pp. 52-76). Norwood, NJ: Ablex Publishing.

Taber, K. S. (2007). Science education for gifted learners? In K. S. Taber (Ed.) Science education for gifted learners (pp. 17-30). New York: Routledge.

Tirri, K., \& Nokelainen, P. (2010). The influence of self-perception of abilities and attribution styles on academic choices: Implications for gifted education. Roeper Review, 33(1), 26-32.

Urhahne, D., Ho, L. H., Parchmann, I., \& Nick, S. (2012). Attempting to predict success in the qualifying round of the International Chemistry Olympiad. High Ability Studies, 23(2), 167-182.

Vock, M., Köller, O., \& Nagy, G. (2012). Vocational interests of intellectually gifted and highly achieving young adults. British Journal of Educational Psychology, 83, 305-328.

Welch, B. L. (1951). On the comparison of several mean values: An alternative approach. Biometrika, 38, 330-336.

Wilding, P. (1995). The changing role of the clinical laboratory scientist: Coming out of the basement. Clinical Chemistry, 41(8), 1211-1214.

\section{Publisher's Note}

Springer Nature remains neutral with regard to jurisdictional claims in published maps and institutional affiliations.

\section{Submit your manuscript to a SpringerOpen ${ }^{\circ}$ journal and benefit from:}

- Convenient online submission

- Rigorous peer review

- Open access: articles freely available online

High visibility within the field

- Retaining the copyright to your article

Submit your next manuscript at $\boldsymbol{\sim}$ springeropen.com 